TP Periodica Polytechnica

42(2), pp. 119-124, 2014

DOI:10.3311/PPtr. 7442

Creative Commons Attribution (1)

RESEARCH ARTICLE
ForFITS: a New Help

\section{in Transport Decision Making for a Sustainable Future}

\author{
Tamás Andrejszki / Miquel Gangonells / Eva Molnar / Ádám Török
}

RECEIVED 24 MARCH 2014

\begin{abstract}
The aim of this study is to present a new software tool which was developed to project activity, energy use and $\mathrm{CO}_{2}$ emissions in the transport sector. The ForFITS (For Future Inland Transport Systems) program was designed to help policy makers to create long-term transport strategies based on forecasted sustainable emission parameters. This article contains information about the basic methodology of the software and shows how useful the simulations are. With using ForFITS after collecting the required data-scenarios of future vehicle stocks, costs, energies used and emissions can be calculated, analyzed and compared. The product of the UNDA project is available for any authority freely so it seems like ForFITS cannot have a competitor in the market.
\end{abstract}

\section{Keywords}

$\mathrm{CO}_{2}$ emission forecasting model $\cdot$ energy consumption $\cdot$ sustainability $\cdot$ transport policy

\section{Tamás Andrejszki}

Department of Transport Technology and Transport Economics, Faculty of Transportation Engineering and Vehicle Engineering, Budapest University of Technology and Economics,

Bertalan L. u. 2., H-1111 Budapest, Hungary

e-mail: tamas.andrejszki@mail.bme.hu

\section{Miquel Gangonells}

Division of Transport, United Nations Economic Commission for Europe, CH-1211 Geneva 10

e-mail: Miquel.Gangonells@unece.org

\section{Eva Molnar}

Division of Transport, United Nations Economic Commission for Europe, CH-1211 Geneva 10

e-mail: Eva.Molnar@unece.org

\section{Ádám Török}

Department of Transport Technology and Transport Economics, Faculty of Transportation Engineering and Vehicle Engineering, Budapest University of Technology and Economics, Bertalan L. u. 2., H-1111 Budapest, Hungary

e-mail: atorok@kgazd.bme.hu

\section{Introduction}

Forecasting future trends at any field of the economy has an essential role in strategy making. If we are able to make a good sophisticated scenario of the future we can plan actions in the right times and in the right fields to control the long-term processes of the examined systems. With this kind of information a competent management of a country or any region is well prepared to keep their managed country or region competitive against their competitors (Cernya et al., 2014).

The mitigation of the $\mathrm{CO}_{2}$ emission (as a part of decreasing the GHG effects) is a global problem; every nation in the World is involved in this process process (Szendro and Torok, 2014). But being environmentally friendly is usually against making the maximal achievable economic growth (Armstrong and Green, 2013). This is the reason why decision-makers need the support of future scenarios to look through: what actions have to be planned and achieved when to reach the optimal level of their environmentally friendly strategy.

In the 2000's SRES model was the most determinative emission-forecasting model. It had 4 main scenarios about the change of economical, social and environmental parameters (Nakićenović and Swart, 2000). Later the RCP-type scenarios became more popular. These scenarios estimate the changes of the concentration of GHG-es in a given time period. CMIP5 (Coupled Model Intercomparison Project Phase 5) promotes a standard set of these model simulations in order to evaluate how realistic the models are in simulating the recent past, provide projections of future climate change on two time scales (near term and long term), and understand some of the factors responsible for differences in model projections (Taylor et al., 2012).

After seeing the guidelines of future scenarios choosing (or knowing) the right ways does not seem to be hard in a global level. But dividing the needed mitigation to economical regions or nations is more sophisticated exercise. In the Impact Assessment of the Low-carbon economy 2050 roadmap the European Union made the decision about which area in which amount should mitigate the $\mathrm{CO}_{2}$ emission (European Commission, 2011a). Transport got its part of this mitigation certainly. 
Virtually all the energy used in transport is obtained from the combustion of oil - based fuels (largely diesel and gasoline): this is why GHG emissions in transport are dominantly $\mathrm{CO}_{2}$ emissions. Transport is responsible for about 13 percent of GHG emissions and 22 percent of the total $\mathrm{CO}_{2}$ emissions from fuel combustion (Barabas and Todorut, 2011; UNDA Seventh Tranche, 2012; Szendro et al., 2012). White Paper 2011 examines four policy options (European Commission, 2011b). Three of them want to reduce $\mathrm{CO}_{2}$ emissions by $60 \%$ over 1990 levels until 2050 and the most pessimistic scenario shows also a little reduction over the 2010 level.

It is trivial that there is a close relation between the energy consumption of transport and the emissions of it. There are studies that examine the driving factors and impacts of transport-related energy consumption (Mraihi et al., 2013, Chandran and Tang, 2013). In Croatia a forecasting model was set up for making future scenarios of Croatian energy consumption related with transport activity (Pukšec et al., 2013).

But how can a government see how much $\mathrm{CO}_{2}$ can be saved by making concrete strategic decisions? How can they know how many percentages of $\mathrm{CO}_{2}$ emission can be reduced by an environmentally friendly transport project? Giving a help for these questions was one of the causes why UNDA project was established: to foster sustainable transport policies: ForFITS (For Future Inland Transport Systems).

In 2008 the UNECE Transport Division called on the UN Development Account (UNDA) for funds to build this project together with all UN Regional Commissions. After the preparation of a global review on existing statistical data, policy measures and assessment tools concerning $\mathrm{CO}_{2}$ emissions in transport a questionnaire was made to provide inputs for the preparation of the review. After the reconciliation with selected experts the first model prototype was released in 2012 (UNECE, 2013).

\section{Methodology}

ForFITS was developed as a software tool capable to satisfy two sets of key requirements:

- the estimation/assessment of emissions in transport;

- the evaluation of transport policies for $\mathrm{CO}_{2}$ emission mitigation.

To achieve these targets, ForFITS evaluates transport activity (expressed in terms of passenger kilometres - pkm, tome kilometres - tkm, and vehicle kilometres - vkm), related vehicle stocks, energy use and $\mathrm{CO}_{2}$ emissions in a range of possible policy contexts.

ForFITS is suitable for the analysis of transport systems having a regional, national and/or local dimension, with a primary focus on national systems.

ForFITS is a sectoral model, covering both passenger and freight transport services on all transport modes (including aviation and maritime transport), but mainly targeting inland transport (especially road, rail, and inland waterways). Pipelines are also considered in the model. Each mode is further characterized in sub-modes (when relevant) and vehicle classes. Vehicle classes are further split to take into account of different powertrain technologies and age classes. Finally, powertrains are coupled with fuel blends that are consistent with the technology requirements (UNECE, 2013).

ForFITS covers several aspects of the transport system, from non-motorized passenger transport to freight pipelines. The following points describe the ranges of parameters covered in ForFITS:

- 2 areas (urban and rural);

- 2 transport services (passenger and freight);

- 9 transport modes;

- 6 vehicle classes;

- 10 fuel blends;

- 31 powertrain technologies;

- 26 age classes.

The technologies of transport modes, powertrains and other related areas are constantly under development. In the input tables of ForFITS there are opportunities to handle these processes by evaluating given factors for the examined 30-year period. In these parameters it is possible to consider the future effects of political supporting (e.g. supporting pedestrian transport transport (Novacko et al., 2014) and the evolution of green corridors (Hunke and Prause, 2013) and technological developments (e.g. alternative fuel technologies (Moeinaddini et al., 2012; Lennox et al., 2013) and wireless energy supply (Graurs et al., 2014).

ForFITS does not provide information on the evaluation of the overall effects of changes in the transport system on the economic growth (UNECE, 2013).

The assessment of emission estimates from fuel consumption is addressed by the multiplication of the energy used by emission factors reflecting the characteristics of the fuels with respect to tank to-wheel and well-to-tank emissions.

The ASIF scheme was originally described in a paper prepared by the IEA on behalf of the World Bank (Schipper et al., 2000; Millard-Ball and Schipper, 2011). It has found prominent application in recent publications of the IEA (Fulton et al., 2009; Brand et al., 2012). ASIF stands for the variables of a generic equation to calculate the GHG emissions of transport that reads:

$$
\mathrm{GHG}=\mathrm{A} \times \mathrm{S} \times \mathrm{I} \times \mathrm{F}
$$

where:

GHG: means the Greenhouse Gas emissions of transport;

A: Vehicle activity (expressed in vkm);

$\mathrm{S}$ : Sectoral structure (expressed as shares of vkm by service, modes, vehicle class and powertrain);

I: Energy Intensity, i.e. the average fuel consumption per vkm by service, mode, vehicle class and powertrain;

F: Carbon Intensity of Fuel blend per unit of energy demand, i.e. well-to-tank and tank-to-wheel emission factors by fuel blend. 
The ASIF equation exists in many variants, a few applying a more aggregate structure (Schafer et al. 2009), but in most cases differentiating some variables of the ASIF equation into more detailed variables (Schiller et al., 2010).

The single components of the ASIF equation can be deduced from the ASTRA model, estimating the total emissions of greenhouse gases from transport. In the following example, only the elements A (activity), I (energy intensity) and F (Fuel/ carbon intensity) are included and modal shares (S), are omitted, so that in fact an A(S)IF approach is applied.

In this case, the ASIF equation is extended as follows:

$$
\sum_{i} F_{i} E F_{i}=A \sum_{i}\left(\frac{A_{i}}{A}\right)\left(\frac{F_{i}}{A_{i}}\right)\left(\frac{E F_{i}}{F_{i}}\right)=A \sum_{i} S_{i} I_{i} E F_{i}=E
$$

With:

$$
E F_{i}=\sum_{j}\left(\frac{E F_{i j}}{F_{i j}}\right)\left(\frac{F_{i j}}{F_{i}}\right)
$$

Where:

E: represents total emissions use in a sector

A: represents overall sectoral activity (vkm)

$\mathrm{A}_{\mathrm{i}} / \mathrm{A}=\mathrm{S}_{\mathrm{i}}$ : represents the sectoral structure (by service, mode, vehicle class and powertrain group)

$\mathrm{F}_{\mathrm{i}} / \mathrm{A}_{\mathrm{i}}=\mathrm{I}_{\mathrm{i}}$ : is the energy intensity (by service, mode, vehicle class and powertrain group)

$\mathrm{EF}_{\mathrm{ij}}$ : is the emission factor per unit of energy for the energy carrier or fuel $\mathrm{j}$ used in the service, mode, vehicle class and powertrain group $i$.

Fig. 1. provides a synthetic description of the calculation flow outlined above, also highlighting the links associated with the ASIF calculations.

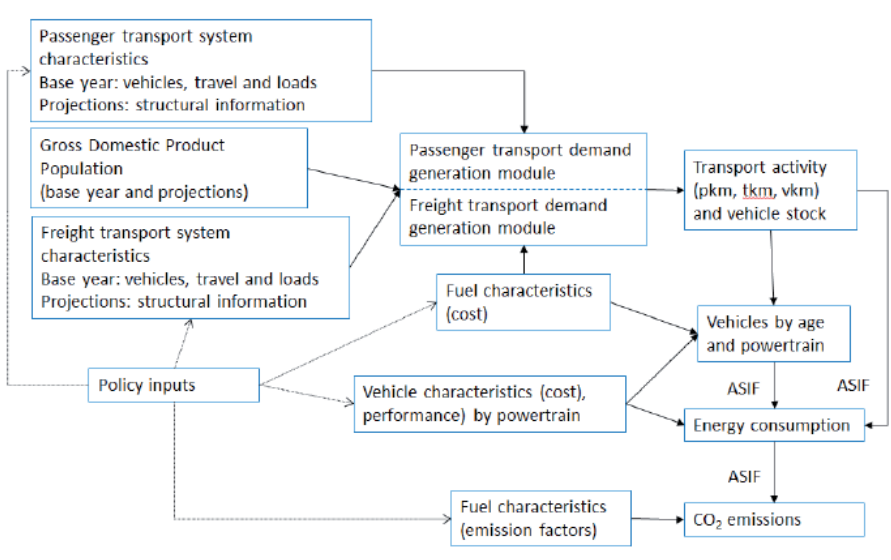

Fig. 1. A synthetic description of the calculation flow (UNECE, 2013)

The model is mainly sensitive to three different aspects:

- Macroeconomic parameters such as GDP and population which are correlated with transport activity;
- Effect of changes in the cost of driving and moving goods through elasticities;

- Structural changes in the transport system (mainly related to the role of public transport in the passenger service in order to assess modal shift policies, and associated to the economy structure in the case of freight transport).

Behavioral aspects and technology choice are also tacked in the model.

\section{Results}

ForFITS was developed in the Vensim modelling environment and is structured in two components: a Vensim Packaged Model file (.vpm) and an Excel file (.xls).

The VPM file is where the model is implemented. Several types of variables are defined by equations and connected between each other by means of arrows. This file takes information from the Inputs Excel file, in which the user must introduce the necessary data to run the model.

The VPM file is structured in ,views" that each one represents a portion of the model. The different views are connected between each other through ,shadow variables" so that the calculations flow goes across the modules (transport demand generation, vehicle stock, energy use and $\mathrm{CO}_{2}$ emissions). The transport demand generation module projects transport activity in terms of $\mathrm{pkm}$ and tkm. This is converted into target vehicle stock by means of information on average vehicle load and average annual vehicle travel. The performance of the new vehicle registrations coming up over time, as well as the mortality curves used to scrap the vehicles, lead to the total energy consumption of the vehicle fleet by fuel blend. Finally, the application of the emission factors enables to estimate the WTW $\mathrm{CO}_{2}$ emissions in the transport sector.

The user interface of the Vensim model is an Excel file organized in different worksheets. These worksheets contain the necessary inputs to run the ForFITS model.

The tool has the capacity to adapt to different levels of data availability. Notwithstanding the possibility to rely on a significant amount of information entered by default in the model, ForFITS requires a minimum amount of data to be properly working.

Minimum input data requirements in ForFITS cover:

- the characterization of the transport system in the base year (historical inputs);

- the definition of the context in which the transport system should evolve when projecting (this includes policy inputs and definition of scenarios).

There are four categories detailing the importance of user involvement in the definition of the data entered into the model:

- $\mathrm{M} \rightarrow$ Data is absolutely required.

- A $\rightarrow$ Inputs expected to be introduced by the user. The current value in the ForFITS Inputs file is for guidance only. This category includes policy inputs that allow exploring different scenarios. 
- $\mathrm{B} \rightarrow$ Input containing a (often technical) default value that may remain unchanged, depending on data availability. Defaults are set on the basis of research activities involving literature reviews and statistical analyses.

- $\mathrm{C} \rightarrow$ Changes to these inputs would likely result in modifications to the structural characteristics of the model. Unless the user acquires sufficient experience, modification of these inputs is highly not recommended.

Each spreadsheet in the Excel file is divided in two parts. On the right half, there is the ,database section” in which the user can create different cases and scenarios by means of introducing data in different tables. On the left side (,selection section"), the user must select what table of those created in the right wants to activate when running the model.

(UNECE, 2013). In this way, the model can be run several times (each time with the set of inputs corresponding to the activated tables) in order to see the impact of various combination of polices and under diverse scenarios.

\section{Analysis}

All the results of a model run/simulation can be visualized in tables or graphs which can be printed or saved as individual files. Tables are stored as text files (TXT), and are easily readable in Excel (e.g. for further analysis). Graphs are stored as images in Windows Metafiles (WMF).

In ForFITS there are 8 output views that show the results stacked and disaggregated in different ways:

- Vehicle stock;

- Activity;

- Energy use;

- Cost;

- Well-to-tank CO2 emissions;

- Tank-to-wheel CO2 emissions;

- Well-to-wheel CO2 emissions;

- New registrations.

In these 8 output views some of the key outputs of ForFITS are shown as graphs. These automatic graphs look like e.g. Fig. 3 where the changing of energy use is shown at the service of passenger transport. The energy uses of each mode are differentiated.

In addition of these output views, the evolution of any variable over time can be visualized. The user needs to select what subscripts of which the variable is disaggregated wants to make appear in the graph. E.g. in Fig. 4 the changing of costs is shown but only in the freight sector.

The points of this graph (the output value at each TIME STEP, normally one year) can be exported to Excel for further analytical work.

The comparison of scenarios can also be done directly in the Vensim program by means of loading several model runs when visualizing the results. In Fig. 5 the well-to-wheel $\mathrm{CO}_{2}$ emissions of freight LDVS (Light Duty Vehicles) are compared according to three different scenarios.

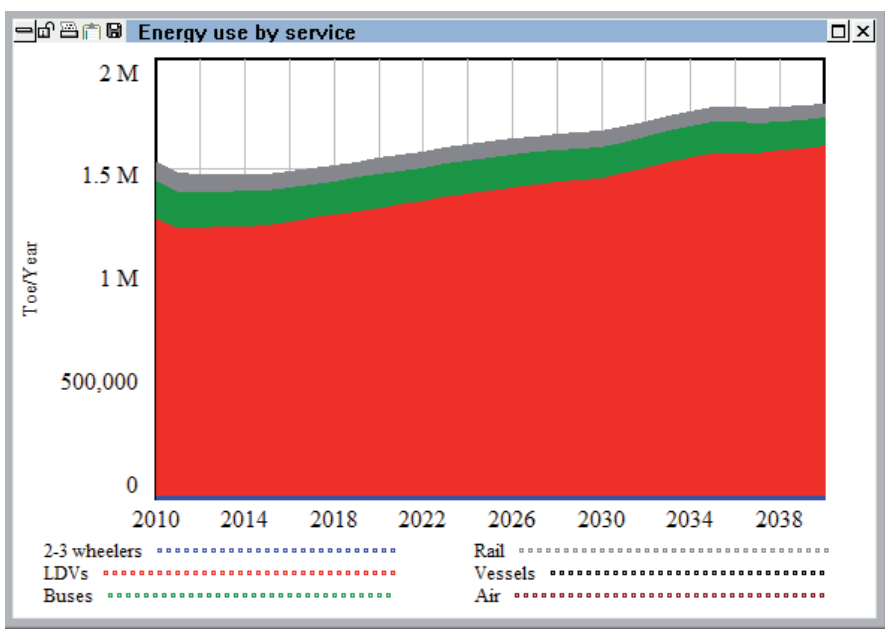

Fig. 2. The forecast of energy use of the passenger transport in a Hungarian scenario

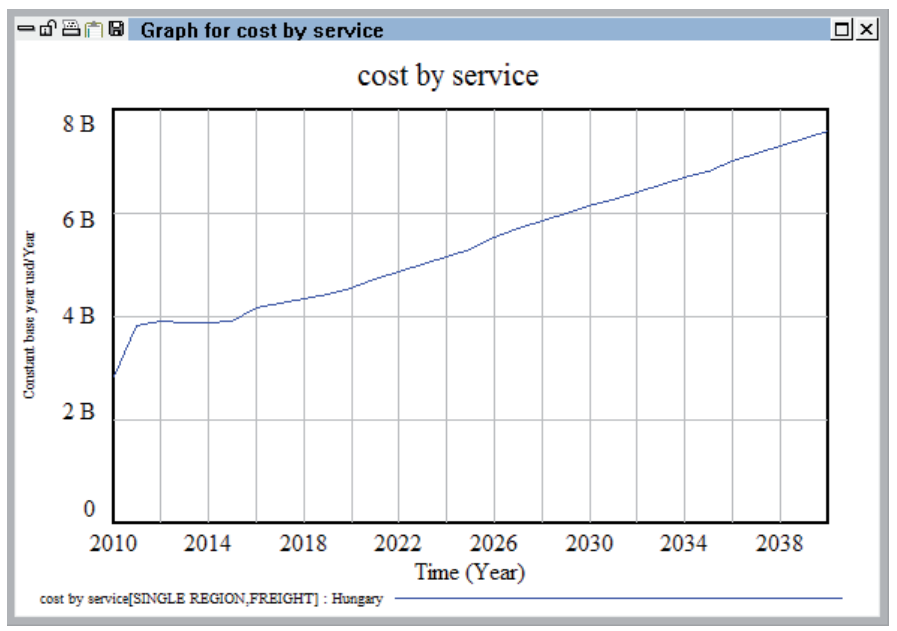

Fig. 3. The forecast of costs of freight transport according to a Hungarian scenario

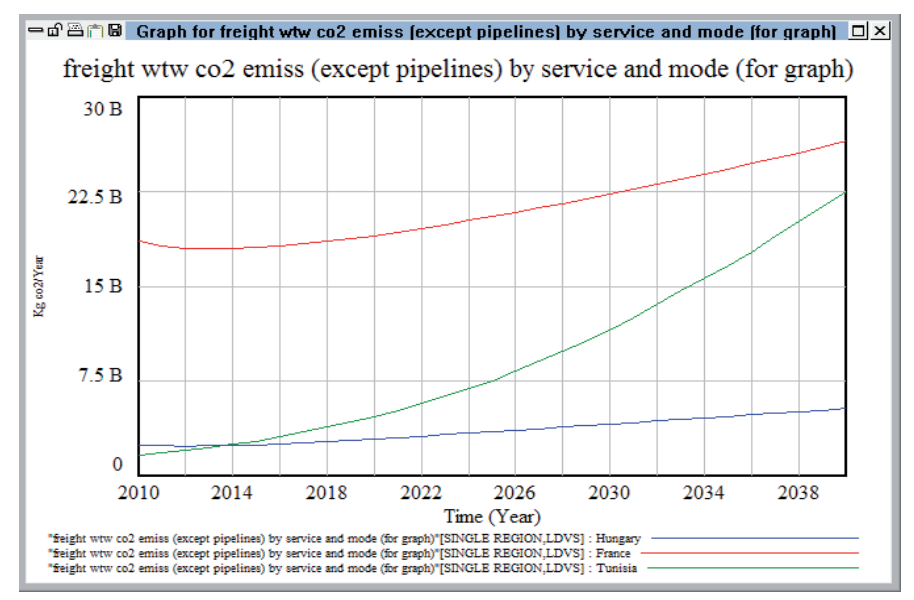

Fig. 4. The comparison of the WTW $\mathrm{CO}_{2}$ emissions of LDVS of freight transport at three scenarios 


\section{Conclusion}

The ForFITS tool is freely downloadable from the UNECE website (http://www.unece.org/trans/theme forfits.html). A user manual that contains all the necessary information related to the use of model is also available at the same page.

The aim of the supporters and designers of ForFITS was to develop a software that responds properly in different socioeconomic contexts and that is able to help strategic decision making in local policies. In this sense, the model was tested in several pilot countries (Chile, Ethiopia, France, Hungary, Montenegro) belonging to the five UN Regions in order to prove the worldwide applicability of the tool.
ForFITS was presented in a number of workshops in the presence of policy makers and technical experts. Several countries representatives showed their interest and their intention to use the model.

However, the ForFITS project is not over yet and expected to continue through mainly two branches: i) Data gathering to further apply the model and subsequent collection of the output results in order to have a broad perspective on $\mathrm{CO}_{2}$ emissions trends and international harmonized strategies to mitigate them; ii) Further development of the model to consider very country specific characteristics as well as further improvement of the tool in terms of accuracy and user friendly. In this sense, the developers of ForFITS are grateful to receive any comment or suggestion.

\section{Acknowledgement}

The project presented in this article is supported by UNECE and the János Bolyai Research Scholarship of the Hungarian Academy of Sciences.

\section{References}

Armstrong J. S. and Green K. C. (2013) Effects of Corporate Social Responsibility and Irresponsibility Policies. Journal of Business Research, 66 (10), pp. 1922-1927. DOI: $10.1016 /$ j.jbusres.2013.02.014

Barabas I. and Todorut I. A. (2011) Predicting the temperature dependent viscosity of biodiesel-diesel-bioethanol blends. Energy \& Fuels, 15 (12), pp. 5767-5774. DOI: $\underline{10.1021 / \mathrm{ef} 2007936}$

Brand C., Tran M. and Anable J. (2012) The UK transport carbon model: An integrated life cycle approach to explore low carbon futures. Energy Policy, 41, pp. 107-124. DOI: 10.1016/j.enpol.2010.08.019

Cerny J., Cerna A. and Linda B. (2014) Support of decision-making on economic and social sustainability of public transport. Transport, 29 (1), pp. 59-68. DOI: $10.3846 / 16484142.2014 .897645$

Chandran V. G. R. and Tang C. F. (2013) The Impacts of Transport Energy Consumption, Foreign Direct Investment and Income on CO2 Emissions in ASEAN-5 Economies. Renewable and Sustainable Energy Reviews, 24, pp. 445-453. DOI: $10.1016 /$ j.rser.2013.03.054

European Commission (2011a) IMPACT ASSESSMENT - Accompanying Document to the Communication from the Commission to the European Parliament, the Council, the European Economic and Social Committee and the Committee of the Regions: A Roadmap for Moving to a Competitive Low Carbon Economy in 2050.

European Commission (2011b) IMPACT ASSESSMENT - Accompanying Document to the WHITE PAPER Roadmap to a Single European Transport Area - Towards a Competitive and Resource Efficient Transport System.

Fulton L., Cazzola P. and Cuenot F. (2009) IEA mobility model (MoMo) and its use in the ETP 2008. Energy Policy, 37, pp. 3758-3768.
Graurs I., Vizulis A., Rubenis A., Laizāns A. (2014) Wireless Energy Supply to Public Transport Units with Hybrid Drive - trends and challenges. Transport and Telecommunication, 15 (1), pp. 67-76. DOI: $10.2478 / \mathrm{ttj}-2014-0007$

Hunke K. and Prause G. (2013) Management of Green Corridor Performance. Transport and Telecommunication, 14 (4), pp. 292-299. DOI: $10.2478 / \mathrm{ttj}-2013-0025$

Lennox S., Lukács K., Torok A., Bereczky A., Mbarawa M., Penninger A., Kolesnikov A. (2013) Combustion and emission characteristics of n-butanol / diesel fuel blend in a turbo-charged compression ignition engine. Fuel, 107, pp. 409-418. DOI: 10.1016/j.fuel.2012.11.083

Millard-Ball A. and Schipper L. (2011) Are We Reaching Peak Travel? Trends in Passenger Transport in Eight Industrialized Countries. Transport Reviews: A Transnational Transdisciplinary Journal, 31 (3), pp. 357-378. DOI: $10.1080 / 01441647.2010 .518291$

Moeinaddini M., Asadi-Sheakri Z. and Zaly Shah M. (2012) The Effectiveness Of Private Motorized Trips Indicators In Reducing Car Usage. International Journal for Traffic and Transport Engineering, 2 (4), pp. 347-358. DOI: $10.7708 / \mathrm{ijtte} .2012 .2(4) .05$

Mraihi R., Abdallah K. and Abid M. (2013) Road transport-related energy consumption: analysis of driving factors in Tunisia. Energy Policy, 62 (11), pp. 247-253. DOI: 10.1016/j.enpol.2013.07.007

Nakicenovic N. and Swart R. (2000) Special Report on Emissions Scenarios: a Special Report of Working Group III of the Intergovernmental Panel on Climate Change. Cambridge/New York: Cambridge University Press.

Novacko L., Petrovic M. and Baric D. (2014) Application Of Macroscopic Modelling In Assessing Noise Level In Urban Areas. International Journal for Traffic and Transport Engineering, 4 (1), pp. 117-127. DOI: $10.7708 / \mathrm{ijtte} .2014 .4(1) .09$ 
Pukšec T., Krajačić G., Lulić Z., Vad Mathiesen B., Duić N. (2013) Forecasting Long-term Energy Demand of Croatian Transport Sector. Energy, 57 (8), pp. 169-176. DOI: $10.1016 /$ j.energy.2013.04.071

Schafer A., Heywood J. B., Jacoby H. D., Waitz I. A. (2009) Transportation in a Climate-Constrained World. London/Cambridge: MIT Press.

Schiller P. L., Brunn E. C. and Kenworthy J. R. (2010) An Introduction to Sustainable Transportation: Policy, Planning, and Implementation, Earthscan. London/Washington.

Schipper L., Marie-Lilliu C. and Gorham R. (2000) Flexing the Link Between Transport and Greenhouse, Gas Emissions. Paris: IEA.

Szendrő G. and Török Á. (2014) Theoretical investigation of environmental development pathways in the road transport sector in the European Region. Transport, 29 (1), pp. 12-17.

DOI: $\underline{10.3846 / 16484142.2014 .893538}$
Szendrö G., Csete M. and Török Á. (2012) Statistical analysis of the road vehicle fleet of Hungary from environmental aspects. Periodica Polytechnica Transportation Engineering, 40 (2), pp. 95-98. DOI: $10.3311 /$ pp.tr.2012-2.09

Taylor K. E., Stouffer R. J. and Meehl G. A. (2012) An Overview of CMIP5 and the Experiment Design. Bulletin of the American Meteorological Society, 93 (4), pp. 485-498.

DOI: 10.1175/BAMS-D-11-00094.1

UNDA Seventh Tranche (2012) CO2 Emissions from Inland Transport: Statistics, Mitigation Polices, and Modelling Tools.

UNECE (2013) "ForFITS - U User Manual." 